the risk of damaging the product due to local overheating. Electronies have brought a contribution in the evaporation of solutions of heat-sensitive materials such as penicillin by means of radio-frequency dielectric heating, in which the heat is generated directly in the liquid concerned. No temperature gradients are present as is the case when an external source of heat is used and heat transfer has to take place through the wall of the container. Radiofrequency heating is not an economic proposition for heating stable liquids, but may prevent serious losses of activity in heat-sensitive ones. Considerable progress had been made in drying; and spraydrying, flash-drying and drum-drying have been developed with considerable success. The so-called freeze-drying has proved extremely valuable in the final stages of drying penicillin. Much attention has been given to the materials used for the construction of plant and storage vessels. Stainless steel has proved extremely useful, but experience has discovered some important defects in its characteristics which require careful attention; thus when it is welded, seeping may develop through the metal on a line parallel to the weld. Research has shown that if stainless steel is kept for a short time at a temperature of about $650^{\circ} \mathrm{C}$., changes in crystalline structure take place which render the material susceptible to cracking on the application of even slight mechanical stress and to corrosion by liquids which will not attack normal stainless steel. Great care must therefore be taken that it is not subjected to conditions which will take from it the right still to be regarded as stainless steel. bf

\section{Institution of Electrical Engineers}

The May issue of Beflournal of the Institution of Electrical Engineers Mntains a foreword with the heading "Sevent/IVe Years", describing the manner in which theigst founder members of the Institution met in May 1871 , "To consider the expediency of H rm Society of Telegraph Engineers, having for it. objoct the general advancement of electrical and telegraphic science and more particularly for facilitating the exchange of information and ideas among its members". At the outset the Society devoted most of its attention to electrical telegraphy, but in 1879 its scope was enlarged and its title changed to "The Society of Telegraph Engineers and Electricians", in order to provide for the interest aroused by the commercial application of electric lighting. With the rapid development of electrical engineering the title was altered again, to "The Institution of Electrical Engineers", in January 1889, when Sir William Thomson, later Lord Kelvin, delivered the first presidential address to the new body, which was granted a royal charter of incorporation in 1921 . During the seventy-five years of its existence, the Institution has become an important and influential body with nearly 13,500 corporate members and more than 15,000 members of other grades on its register. With the aid of the specialized sections formed in recent years to deal with the fields of installations, measurements, radio and transmission, the Institution caters for this vast membership by pursuing a steady, but vigorous, policy of promoting the general advancement of electrical science and engineering and their applications.

The following have been elected officers of the Institution of Electrical Engineers for 1946-47: President: V. Z. de Ferranti; Vice-Presidents : J. Hacking, T. Graeme N. Haldane, Prof. E. B.
Moullin; Honorary Treasurer: E. Leete; New Members of Council: Dr. T. E. Allibone, D. B. Hoseason, Col. B. H. Leeson, H. Nimmo (members); C. S. Briggs, Dr. F. C. Williams (associate members); . G. Wansbrough (companion). \section{Joints and Sealing nds for Pressure Cablè}

A PAPER by Dpr I. G. Brazier, read in London before the Institat on of Electrical Engineers, discusses the genefer of inciples involved in the design of joints gudseafing ends for pressure-cable installations. Dpsigs standards based on experimeńtal results are g won, and practical methods of construction are described. An account is also given of the gas-control accessories of a pressure cable, including leak location methods. Special attention is given to the problem of voltage surges in relation to joints and sealing ends, and it is shown that the voltage surges specified as representing service conditions are now a critical factor determining the amount of insulation. The relative economics of providing for the voltage surges by additional insulation or alternatively by surge diverters are examined.

\section{A Scottish Statistical Research Bureau}

A Scottish Sphitstical Research Bureau has been set up infolnourgh, following discussions which have tak place between the four Scottish universipips ofd the Faculty of Actuaries. Its object is to plat statistical experience and advice at the disposal of research workers in possession of statistical material. The Bureau functions through a Central Committee, of which the first chairman is Mr. J. G. Kyd, Registrar-General for Scotland and lately president of the Faculty of Actuaries. The secretary is Mr. E. Waugh, Faculty of Actuaries, $23 \mathrm{St}$. Andrew Square, Edinburgh.

Prehistory in South Africa

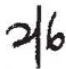

THE first number of a new series of bulletins of the South Africapt Archæological Society, Cape Town, will be of gentotinterest to all prehistorians. These bulletin f will not be confined exclusively to South African Ctudies, but will embrace accounts of research d f cin other areas. The first bulletin, for example, not only describes a preliminary survey of work in South Africa and discusses colour in prehistoric rock paintings, but also includes an account by J. d'A. Waechter of an archæological excavation in the Middle East, and a brief note on the mesolithic cultures of Britain. These bulletins will help to link up more closely South African archæologists, and also act as a convenient medium between them and their colleagues in other countries.

A Blue Moon

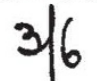

Sky and Telescope for March has an article by J. Hugh Pruett "f the title "Once in a Blue Moon", in which thene is a discussion of the origin of the expresfon ${ }^{\text {t }}$ The chief interest in the article consists, nets 11 me in referring to the theories regarding the orifin of 'a blue moon', as in providing irrefutable evldend from several sources that a blue moon has actually been observed on different occasions. The author of the article states that he saw the phenomenon himself on July 28, 1944. The moon was at the first-quarter phase that day and was thinly veiled by a small patch of high cirrus clouds which were tinted a beautiful orange-red by the sun just below the horizon. It was thought that the lunar blue might be the effect of contrast with the red of the clouds, but this view was shown to be incorrect 